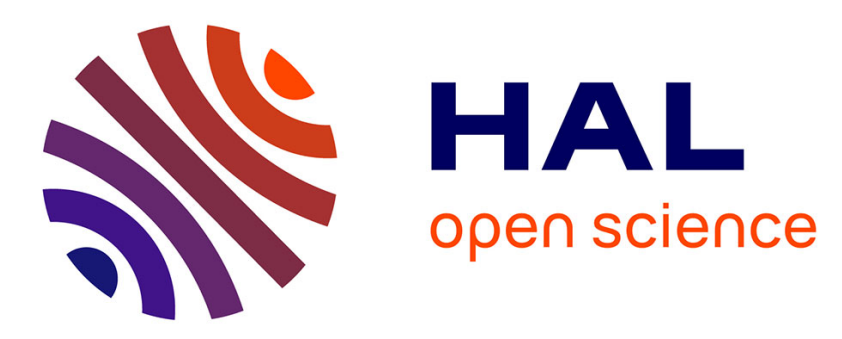

\title{
Understanding the different (dis)charging steps of supercapacitors: influence of potential and solvation
}

\author{
Clarisse Péan, Benjamin Rotenberg, Patrice Simon, Mathieu Salanne
}

\section{To cite this version:}

Clarisse Péan, Benjamin Rotenberg, Patrice Simon, Mathieu Salanne. Understanding the different (dis)charging steps of supercapacitors: influence of potential and solvation. Electrochimica Acta, 2016, vol. 206, pp. 504-512. 10.1016/j.electacta.2016.02.106 . hal-01473671

\section{HAL Id: hal-01473671 \\ https://hal.science/hal-01473671}

Submitted on 22 Feb 2017

HAL is a multi-disciplinary open access archive for the deposit and dissemination of scientific research documents, whether they are published or not. The documents may come from teaching and research institutions in France or abroad, or from public or private research centers.
L'archive ouverte pluridisciplinaire HAL, est destinée au dépôt et à la diffusion de documents scientifiques de niveau recherche, publiés ou non, émanant des établissements d'enseignement et de recherche français ou étrangers, des laboratoires publics ou privés. 


\section{OATAO \\ Open Archive Toulouse Archive Ouverte}

\section{Open Archive TOULOUSE Archive Ouverte (OATAO)}

OATAO is an open access repository that collects the work of Toulouse researchers and makes it freely available over the web where possible.

This is an author-deposited version published in : http://oatao.univ-toulouse.fr/ Eprints ID : 16646

To link to this article : DOI:10.1016/j.electacta.2016.02.106

URL : http://dx.doi.org/10.1016/j.electacta.2016.02.106

To cite this version : Péan, Clarisse and Rotenberg, Benjamin and Simon, Patrice and Salanne, Mathieu Understanding the different (dis)charging steps of supercapacitors: influence of potential and solvation. (2016) Electrochimica Acta, vol. 206. pp. 504-512. ISSN $0013-4686$

Any correspondence concerning this service should be sent to the repository administrator: staff-oatao@,listes-diff.inp-toulouse.fr 


\title{
Understanding the different (dis)charging steps of supercapacitors: influence of potential and solvation
}

\author{
C. Pean ${ }^{a, b, c, *}$, B. Rotenberg ${ }^{a, c}$, P. Simon ${ }^{b, c}$, M. Salanne ${ }^{a, c, d}$ \\ a Sorbonne Universités, UPMC Université Paris 06, UMR 8234, PHENIX, F-75005 Paris, France \\ b CIRIMAT, UMR CNRS 5085, Université Paul Sabatier, F-31062 Toulouse, France

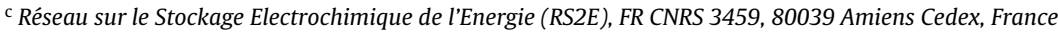 \\ ¿ Maison de la Simulation, USR 3441, CEA - CNRS - INRIA - Université Paris Sud - Université de Versailles, F-91191 Gif-sur-Yvette, France
}

Keywords:

Supercapacitors

Dynamic processes

Molecular dynamics

Porous materials

Solvation

\begin{abstract}
A B S T R A C T
Supercapacitors are an innovative and promising technology in the field of energy storage. In the present study, we use modeling via computer simulation as a technique to study the dynamic processes of charging and discharging. This methodology is complementary to experiments. Various model systems composed of different structures of carbon electrodes, in contact with either pure or solvated ionic liquid, polarized at positive or negative potentials were investigated. From the data obtained, we identify several characteristic times for the charging mechanism of supercapacitors. Furthermore, we determine the influence of the structure of the electrode material, and the effects of potential and solvation on dynamical processes.
\end{abstract}

\section{Introduction}

Supercapacitors, also known as Electrical Double-Layer Capacitors (or EDLCs), are powerful and promising electrochemical storage systems [1]. In particular, it has been shown that nanoporous carbon-based supercapacitors exhibit very high capacitances [2]. Various experimental techniques allow to investigate supercapacitors: among them, the most powerful are, in addition to electrochemical methods, EQCM [3], classical NMR [4,5], solid state NMR [6], infrared spectroscopy [7], SAXS and SANS [8,9]. For all experimental techniques though, it is difficult to get detailed and quantitative information at the molecular level. In contrast, molecular simulations allow to analyse finely the processes at the molecular scale, since it provides the position of all the atoms over time. The two methodologies are then complementary. Among the numerous computational studies that have already been published on supercapacitors, electrodes can be simulated as planar structures [10,11], slit pores [12-14], or regular carbon chains [15]. All these models are idealized and the models with complex disordered electrodes are closer to experimental reality. Here, we simulate nanoporous carbide derived carbon (CDC) electrodes. In particular, with the latter it has been possible to explain the high

\footnotetext{
* Corresponding author.

E-mail address: clarisse.pean@gmail.com (C. Pean).
}

capacitance exhibited by nanoporous carbon based supercapacitors [16]. Complex nanoporous electrodes are more difficult to simulate, on the one hand because they are not easy to generate and on the other hand because it is computationally more demanding to work with disordered systems involving a large number of atoms. Furthermore, it is not as easy as with planar structures to measure their performances. To calculate the accurate capacitance of a nanoporous disordered electrode, it is necessary to use a planar electrode as a counter electrode with which the Poisson potential can be defined [17]. Several studies on the equilibrium arrangement of the species inside supercapacitors electrodes have already been carried out in our group $[18,19]$. Furthermore, the effect of solvation on static properties (structure of the liquid, global capacitances, density profiles) have been studied on planar electrodes [20]. Despite such significant progress, a real difficulty in the electrochemical study of supercapacitors remains to apprehend dynamical processes, either experimentally or by simulation. Kornyshev et al. investigated the transport properties inside slit pores [21,22]. Currently, only few experimental techniques give access to dynamical properties, e.g. EQCM [23], infrared spectroelectrochemistry [7,24] and NMR [25].

In this work we use a realistic model to investigate by classical molecular simulations the dynamical behaviour of EDLCs: carbon electrodes are made of complex CDCs, in contact with either pure or solvated ionic liquid $[\mathrm{BMI}]\left[\mathrm{PF}_{6}\right]$. The model allows for the polarization of the electrodes, and thus to work with a constant potential 
[26], as it is the case experimentally. We already showed that these model systems were reliable because they allow to calculate reasonable charging times for corresponding macroscopic devices [27]. Here, we perform out-of-equilibrium simulations that simulate the charging and discharging of supercapacitors. Charging and discharging are initiated by a perturbation, namely a sudden change in the potential difference. The path to return to equilibrium is then analyzed. The evolution of characteristic quantities, such as the number of ions inside the electrodes, the distance of the electrolyte molecules to the carbon surface or the degree of confinement of the ions [28] can be monitored as a function of time. By comparing the behaviour of pure and solvated systems charged at different voltages, we are able to conclude on the effects of solvation and of high potentials on the dynamics of charging and discharging. Furthermore, we are able to identify a stepwise mechanism for the charging process.

\section{Computational Details}

The simulation cells consists of $[\mathrm{BMI}]\left[\mathrm{PF}_{6}\right]$ ionic liquid (600 ion pairs) or $[\mathrm{BMI}]\left[\mathrm{PF}_{6}\right]$ solvated in acetonitrile (230 ion pairs among 2146 acetonitrile molecules, corresponding to a concentration of $1.5 \mathrm{M}$ that is classically used in experiments) surrounded by two identical and symmetric nanoporous carbon electrodes, obtained by quenched molecular dynamics [29]. For the pure ionic liquid, three different CDC electrode materials are considered (see Table 1). Following our previous works, we use for the ionic liquid the coarsegrained model of Roy and Maroncelli, which yields the correct structural, thermodynamic and dynamic properties of $[\mathrm{BMI}]\left[\mathrm{PF}_{6}\right]$ $[30,31]$. Three and one sites describe the cation and the anion, respectively $[18,19]$. For acetonitrile, also following our previous work, the coarse-grained model is the one of Edwards et al. [32]. The size of the simulation cells in the $z$ direction are chosen in order to reproduce the experimental densities of the bulk electrolyte.

Molecular dynamics simulations are conducted on the four different systems described in table 1 , with a timestep of $2 \mathrm{fs}$ which is consistent with the coarse-grained models used. The forces are calculated as the sum of site-site Lennard-Jones and coulombic interactions. Parameters for the ions and carbon atoms are the same as in our previous work [16]. In all the simulations, the Coulomb interactions are calculated through a two-dimensional Ewald summation $[33,34]$. The lengths in the $x$ and $y$ directions are the same (two dimensional periodic boundary conditions are used, i.e. there is no periodicity in the $z$ direction).

The procedure to simulate the charging process consists in two steps: The system is first equilibrated for a few nanoseconds, first with a constant charge of 0 e on all carbon atoms and then with a $0 \mathrm{~V}$ potential difference between the two electrodes. Then at $t=0$, this potential difference $\Delta \psi^{0}$ is suddenly set to 1,2 or $4 \mathrm{~V}\left(\psi^{+}=\Delta \psi^{0} / 2\right.$ and $\left.\psi^{-}=-\Delta \psi^{0} / 2\right)$ and maintained constant. The discharging process is simulated the opposite way: starting from the end of the charging simulations, at $t=0$, the difference $\Delta \psi^{0}$ is suddenly set to 0 and maintained constant. The electrodes are held at constant potential using a method developed by Reed et al. [33] from an original proposal by Siepmann [35]. Simulations are continued enough time to reach equilibrium, i.e. to exhibit a long plateau for the value of the total charge on carbon atoms. The constant potential approach is computationally expensive compared to the constant charge approach but is compulsory to study realistically dynamic processes [26].

The simulations are performed in the NVE ensemble. The pure ionic liquid and the solvated one are simulated at $400 \mathrm{~K}$ and $298 \mathrm{~K}$ respectively. These temperatures are chosen because of the very high viscosity of $[\mathrm{BMI}]\left[\mathrm{PF}_{6}\right]$ at room temperature (261.4 $\mathrm{mPa}$.s for [BMI][PF6] [36]) and because acetonitrile boils at $355 \mathrm{~K}$. Furthermore, at these temperatures we have equivalent mobilities for the ions. Even if the simulated temperatures are different, qualitative comparisons can be done between solvated and pure ionic liquids. The qualitative conclusions on the charging and discharging mechanisms are still valid because we identify mechanisms that are found for different temperatures. Indeed, high potential simulations $(4 \mathrm{~V})$ exhibit temperature elevation along the simulation, explained by the Joule effect [26]. The data presented in this article show that mechanisms are qualitatively the same for low or high potential differences, thus proving the weak effect of temperature here.

\section{Results and Discussion}

\subsection{Charges on carbon atoms}

Fig. 1 shows the evolution of the total charges on the carbon atoms of either the positive or the negative electrode (both are opposite because of the electroneutrality of the global system) during charging processes at different voltages or discharging on CDC-1200. A higher potential difference allow to reach a larger plateau value at the end of the simulation. During the charging, the total charge of the positive electrode increases, first very fast, and then more slowly, for all potential differences, according to our previous results [27]. In the latter work, we describe the use of an equivalent circuit model to interpret the evolution of the total charges on carbon atoms. The charging plots were fitted accurately by a biexponentional function. This work allowed to demonstrate that our simulations are performed on a time scale that is consistent with the size of our model systems. Here, in order to make comparisons between characteristic times for different quantities, we choose the simplest model of a monoexponential fit with the general expression for the charge during charging: $Q(t)=Q_{\max } \cdot(1-\exp (-t / \tau))$. Indeed, if the principal aim is to compare different systems and extract their qualitative behaviour, the fit does not need to be extremely accurate. From the values of the characteristic times $\tau$ presented on the top of Fig. 1, we can conclude that the higher the potential is, the faster the stationary state is reached. Furthermore, the integral capacitance $C_{\text {int }}=\frac{\left\langle Q_{\text {tot }}\right\rangle}{\Delta \Psi}$ only slightly depends on the applied potential difference. We also note that when the potential is high, the monoexponential function really suits the raw data.

Then we compare the values of the $\tau$ for the charging of CDC1200 in contact with either pure or solvated ionic liquid (Fig. 1, bottom). In both cases, we have $\tau \approx 970 \mathrm{ps}$, revealing the same kinetics for the charging process at this concentration of acetonitrile of $1.5 \mathrm{M}$ and at these simulated temperatures (298 K for acetonitrile

Table 1

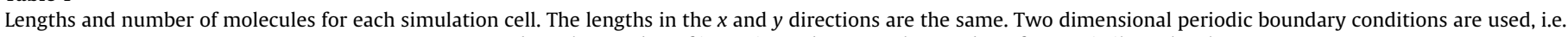
there is no periodicity in the $z$ direction. $\mathrm{N}_{\text {ions }}$ corresponds to the number of ion pairs and $\mathrm{N}_{\mathrm{ACN}}$ to the number of acetonitrile molecules.

\begin{tabular}{|c|c|c|c|c|c|}
\hline Systems & $L_{x}=L_{y}(\mathrm{~nm})$ & $L_{z}(\mathrm{~nm})$ & $\mathrm{N}_{\mathrm{C}}$ & $\mathrm{N}_{\text {ions }}$ & $\mathrm{N}_{\mathrm{ACN}}$ \\
\hline CDC-1200/[BMI][PF 6$]$ & 4,37 & 18,64 & 3649 & 600 & - \\
\hline CDC-950/[BMI] $\left[\mathrm{PF}_{6}\right]$ & 4,36 & 18,64 & 3276 & 600 & - \\
\hline $\mathrm{CDC}-800 /[\mathrm{BMI}]\left[\mathrm{PF}_{6}\right]$ & 4,33 & 18,55 & 3821 & 600 & - \\
\hline $\mathrm{CDC}-1200 / \mathrm{ACN}-[\mathrm{BMI}]\left[\mathrm{PF}_{6}\right]$ & 4,37 & 19,44 & 3649 & 230 & 2146 \\
\hline
\end{tabular}



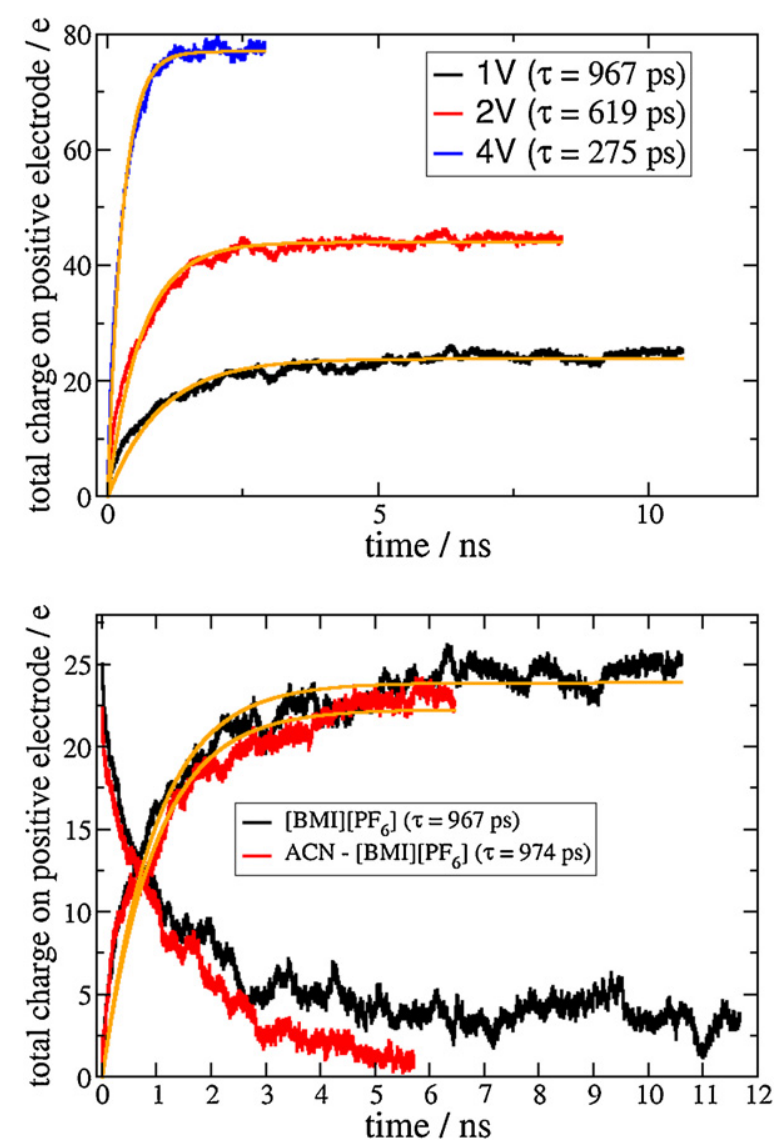

Fig. 1. Top: evolution of the charge on the positive electrode of CDC-1200 in contact with pure $[\mathrm{BMI}]\left[\mathrm{PF}_{6}\right]$ for charging processes at three different potential differences: 1 (black), 2 (red) and $4 \mathrm{~V}$ (blue). Bottom: evolution of the charge on the positive electrode of CDC-1200 during charging or discharging processes in the case of pure $[\mathrm{BMI}]\left[\mathrm{PF}_{6}\right]$ (black) or solvated in acetonitrile (red). The monoexponential fits are in orange.

and $400 \mathrm{~K}$ for pure ionic liquid). Here, the solvent does not have an effect on the charging dynamics at the electrode scale. The plateau values reached at the end of the simulation are the same, indicating that the capacitance are close for the two systems, in agreement with our previous results [20] where the gravimetric capacitance was of $87 \mathrm{~F} / \mathrm{g}$ for the system with pure ionic liquid and $80 \mathrm{~F} / \mathrm{g}$ for the system with solvent.

We can then compare the charging and the discharging (Fig. 2). At first glance, the two processes seem really symmetric, the charging ending at around $25 \mathrm{e}$ and the crossing between charging and discharging occuring at $12.5 \mathrm{e}$. To analyze in further detail the two mechanisms, we separate each electrode into four slices of same volume, and sum slice per slice the values of the charges for both the charging and the discharging. The results of the sum consists in four globally constant plots. This methodology allows us to compare the kinetics of the charging and discharging phenomena in a trustful way because we do not assume any mathematical function to describe the evolution of the charges on atoms. The four plots obtained are constant, which reveals that the charging and the discharging happen with the same kinetics.

\subsection{Number of atoms inside the electrodes}

In the tables of Fig. 3, we examine the total number of ions inside the electrodes at the initial and final states of the simulation, in cases of pure ionic liquid. A non charged state is characterized by a small difference between cations and anions $(|\boldsymbol{C}-\boldsymbol{A}| \leq 5)$, whereas charged states are characterized by a larger difference

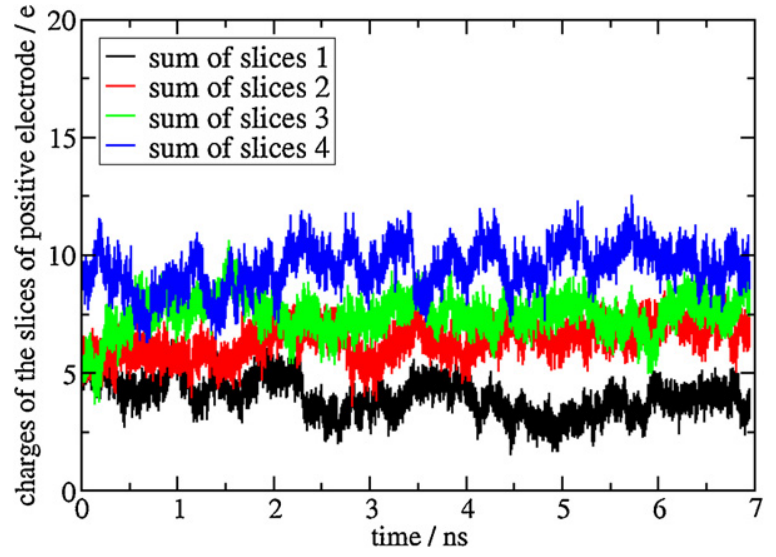

Fig. 2. Sum slice to slice (slice 1 correspond to the deepest slice in the electrode, slice 4 is the slice at the interface) of the values of the charges on the carbon atoms on the positive electrode during charging and discharging processes. The four plots obtained are globally constant, which suggests that the two processes are symmetric.

which depends on the applied potential difference. The sum $\boldsymbol{C}+\boldsymbol{A}$ is not particularly important with high potential differences. Furthermore, it fluctuates with no clear tendency (the standard deviation is around 5) between initial and final states, confirming the exchange of ions between the electrode and the bulk during the charging process, already highlighted in our previous work [16].

For CDC-1200, during the charging process at $1 \mathrm{~V}$, the number of counter-ions increases by $20-35 \%$ for the anions, by $10-20 \%$ for the cations, and the number of co-ions decreases by $20 \%$ for the anions, and slightly less than $10 \%$ for the cations. Cations are therefore less mobile than anions, according to their more complex geometry and their larger size. Symmetrically, for the discharging, we observe larger variations for anions (by 20 - 25\%) than for cations (a little more than 10\%). The final state of the discharging is similar to the initial state of the charging, even though not identical, consistently with the fact that the latter has been obtained by the constant charges methodology [26].

We now consider the simulations with solvent (tables of Fig. 4). The number $\boldsymbol{C}-\boldsymbol{A}$ is very similar in the cases with or without solvent, according to the values of the charges on electrodes (Fig. 1). The number $\boldsymbol{C}+\boldsymbol{A}$ is smaller in the presence of solvent, because there are less ions in the simulation cells with acetonitrile. It is therefore possible to have the same value of the charge on the electrode with fewer ions, if we add solvent to the system. As the charging and discharging plots of Fig. 1 are very similar with or without acetonitrile, one hypothesis would have been to think that acetonitrile is not present in the electrodes. From the number of molecules in the tables of Fig. 4, we see that it is not the case at all. Inside the electrodes, $80 \%$ of the molecules are acetonitrile molecules, i.e. only marginally less than in the bulk (90\%). Furthermore, we notice that, along the charging and discharging processes, the number of acetonitrile molecules stays almost constant, which was also recently evidenced from combined EQCM/NMR experiments $[23,25]$.

The evolution as a function of time of the number of anions and cations, for a charging process at a $4 \mathrm{~V}$ potential difference, is presented in Fig. 5. As for smaller potential differences, two regimes are observed: a first one where the number of ions changes quickly, and a second regime where it evolves slowly. As done above for the charges on the electrodes, it is possible to fit the evolution of the number of ions by a monoexponential function. The characteristic times $\tau$ are given on Fig. 5. They are all of the same order of magnitude (around $300 \mathrm{ps)}$ ) and very close to that obtained for the charging at $4 \mathrm{~V}$. The two phenomena (total charge on electrode and 


\begin{tabular}{|c|c|c|c|c|c|}
\hline \multirow{2}{*}{\multicolumn{2}{|c|}{ Charging ( $0 \mathrm{~V}$ to $1 \mathrm{~V})$}} & \multicolumn{2}{|c|}{ Elec + } & \multicolumn{2}{|c|}{ Elec - } \\
\hline & & \multirow{2}{*}{\begin{tabular}{r|}
$\mathbf{t}=\mathbf{0}$ \\
92
\end{tabular}} & \multirow{2}{*}{$\frac{t=\mathbf{t}_{\mathbf{f}}}{125}$} & \multirow{2}{*}{\begin{tabular}{c|}
$\mathbf{t}=\mathbf{0}$ \\
94
\end{tabular}} & \multirow{2}{*}{$\frac{\mathbf{t}=\mathbf{t}_{\mathbf{f}}}{77}$} \\
\hline \multirow{4}{*}{$\begin{array}{l}\mathrm{CDC} 1200 / \\
{[\mathrm{BMI}]\left[\mathrm{PF}_{6}\right]}\end{array}$} & $A$ & & & & \\
\hline & $C$ & 93 & 87 & 92 & 111 \\
\hline & $C-A$ & 1 & -38 & -2 & 34 \\
\hline & $C+A$ & 185 & 212 & 186 & 188 \\
\hline \multirow{4}{*}{$\begin{array}{c}\mathrm{CDC} 950 / \\
{\left[\mathrm{BMI}_{[}\left[\mathrm{PF}_{6}\right]\right.}\end{array}$} & $A$ & 102 & 119 & 93 & 85 \\
\hline & $C$ & 100 & 90 & 94 & 117 \\
\hline & $C-A$ & \begin{tabular}{|l|}
-2 \\
\end{tabular} & -29 & 1 & 32 \\
\hline & $C+A$ & 202 & 209 & 187 & 202 \\
\hline \multirow{4}{*}{$\begin{array}{c}\text { CDC } 800 / \\
{\left[\mathrm{BMI}_{[}\left[\mathrm{PF}_{6}\right]\right.}\end{array}$} & $A$ & 80 & 98 & 76 & 60 \\
\hline & $C$ & 82 & 69 & 73 & 85 \\
\hline & $C-A$ & 2 & -29 & -3 & 25 \\
\hline & $C+A$ & 162 & 167 & 149 & 145 \\
\hline
\end{tabular}

\begin{tabular}{|c|c|c|c|c|c|}
\hline \multirow{2}{*}{\multicolumn{2}{|c|}{ Charging $(0 \mathrm{~V}$ to $2 \mathrm{~V})$}} & \multicolumn{2}{|c|}{ Elec + } & \multicolumn{2}{|c|}{ Elec - } \\
\hline & & $t=0$ & $t=t_{f}$ & $\mathrm{t}=\mathbf{0}$ & $\mathbf{t}=\mathbf{t}_{\mathrm{f}}$ \\
\hline \multirow{4}{*}{$\begin{array}{l}\mathrm{CDC} 1200 / \\
{[\mathrm{BMI}]\left[\mathrm{PF}_{6}\right]}\end{array}$} & $A$ & 92 & 129 & 94 & 64 \\
\hline & $C$ & 93 & 73 & 92 & 122 \\
\hline & $C-A$ & 1 & -56 & -2 & 58 \\
\hline & $C+A$ & 185 & 202 & 186 & 186 \\
\hline \multirow{4}{*}{$\begin{array}{c}\text { CDC 950 / } \\
{\left[\mathrm{BMI}_{[}\left[\mathrm{PF}_{6}\right]\right.}\end{array}$} & $A$ & 102 & 131 & 93 & 67 \\
\hline & $C$ & 100 & 82 & 94 & 118 \\
\hline & $C-A$ & -2 & -49 & 1 & 51 \\
\hline & $C+A$ & 202 & 213 & 187 & 185 \\
\hline \multirow{4}{*}{$\begin{array}{c}\mathrm{CDC} 800 \text { / } \\
{[\mathrm{BMI}]\left[\mathrm{PF}_{6}\right]}\end{array}$} & $A$ & 80 & 114 & 76 & 51 \\
\hline & $C$ & 82 & 56 & 73 & 108 \\
\hline & $C-A$ & 2 & -58 & -3 & 57 \\
\hline & $C+A$ & 162 & 170 & 149 & 159 \\
\hline
\end{tabular}

\begin{tabular}{|c|c|c|c|c|c|}
\hline \multirow{2}{*}{\multicolumn{2}{|c|}{ Charging $(0 \mathrm{~V}$ to $4 \mathrm{~V})$}} & \multicolumn{2}{|c|}{ Elec +} & \multicolumn{2}{|c|}{ Elec - } \\
\hline & & \multirow{2}{*}{$\begin{aligned} \mathbf{t}=\mathbf{0} \\
92 \\
\end{aligned}$} & \multirow{2}{*}{$\begin{array}{c}\mathrm{t}=\mathbf{t}_{\mathrm{f}} \\
156\end{array}$} & \multirow{2}{*}{\begin{tabular}{r|}
$\mathbf{t}=\mathbf{0}$ \\
94 \\
\end{tabular}} & \multirow{2}{*}{$\frac{t=t_{f}}{40}$} \\
\hline \multirow{4}{*}{$\begin{array}{l}\mathrm{CDC} 1200 / \\
{[\mathrm{BMI}]\left[\mathrm{PF}_{6}\right]}\end{array}$} & $A$ & & & & \\
\hline & $C$ & 93 & 63 & 92 & 139 \\
\hline & $C-A$ & 1 & -93 & -2 & 99 \\
\hline & $C+A$ & 185 & 219 & 186 & 179 \\
\hline \multirow{4}{*}{$\begin{array}{c}\text { CDC 950 / } \\
{\left[\mathrm{BMI}_{[}\left[\mathrm{PF}_{6}\right]\right.}\end{array}$} & $A$ & 102 & 159 & 93 & 42 \\
\hline & $C$ & 100 & 67 & 94 & 124 \\
\hline & $C-A$ & -2 & -92 & 1 & 82 \\
\hline & $C+A$ & 202 & 226 & 187 & 166 \\
\hline \multirow{4}{*}{$\begin{array}{c}\text { CDC 800 / } \\
{\left[\mathrm{BMI}_{[}\left[\mathrm{PF}_{6}\right]\right.}\end{array}$} & $A$ & 80 & 152 & 76 & 29 \\
\hline & C & 82 & 48 & 73 & 131 \\
\hline & $C-A$ & 2 & -104 & -3 & 102 \\
\hline & $C+A$ & 162 & 200 & 149 & 160 \\
\hline
\end{tabular}

\begin{tabular}{|c|c|c|c|c|c|}
\hline \multirow{2}{*}{\multicolumn{2}{|c|}{ Discharging (1V to $0 \mathrm{~V})$}} & \multicolumn{2}{|c|}{ Elec + } & \multicolumn{2}{|c|}{ Elec - } \\
\hline & & $\mathbf{t}=\mathbf{0}$ & $t=t_{f}$ & $t=0$ & $t=t_{f}$ \\
\hline \multirow{4}{*}{$\begin{array}{l}\text { CDC 1200/ } \\
{\left[\text { BMI] }\left[\mathrm{PF}_{6}\right]\right.}\end{array}$} & $A$ & 125 & 102 & 77 & 92 \\
\hline & $C$ & 87 & 98 & 111 & 96 \\
\hline & $C-A$ & -38 & -4 & 34 & 4 \\
\hline & $C+A$ & 212 & 200 & 188 & 188 \\
\hline
\end{tabular}

\begin{tabular}{|c|c|c|c|c|c|}
\hline \multirow{2}{*}{\multicolumn{2}{|c|}{ Discharging (2V to 0V) }} & \multicolumn{2}{|c|}{ Elec +} & \multicolumn{2}{|c|}{ Elec - } \\
\hline & & $\mathbf{t}=\mathbf{0}$ & $t=t_{f}$ & $\mathbf{t}=\mathbf{0}$ & $\mathbf{t}=\mathbf{t}_{\mathrm{f}}$ \\
\hline \multirow{4}{*}{$\begin{array}{l}\text { CDC 1200/ } \\
{[\text { [BMI][PF } 6]}\end{array}$} & $A$ & 129 & 100 & 64 & 93 \\
\hline & $C$ & 73 & 94 & 122 & 95 \\
\hline & $C-A$ & -56 & -6 & 58 & 2 \\
\hline & $C+A$ & 202 & 194 & 186 & 188 \\
\hline \multirow{4}{*}{$\begin{array}{c}\mathrm{CDC} 950 / \\
{[\mathrm{BMI}]\left[\mathrm{PF}_{6}\right]}\end{array}$} & $A$ & 131 & 102 & 67 & 97 \\
\hline & $C$ & 82 & 102 & 118 & 99 \\
\hline & $C-A$ & -49 & 0 & 51 & 2 \\
\hline & $C+A$ & 213 & 204 & 185 & 196 \\
\hline
\end{tabular}

\begin{tabular}{|c|c|c|c|c|c|}
\hline \multirow{2}{*}{\multicolumn{2}{|c|}{ Discharging $(4 \mathrm{~V}$ to $0 \mathrm{~V})$}} & \multicolumn{2}{|c|}{ Elec +} & \multicolumn{2}{|c|}{ Elec - } \\
\hline & & $\mathbf{t}=\mathbf{0}$ & $t=t_{f}$ & $t=0$ & $t=t_{f}$ \\
\hline \multirow{4}{*}{$\begin{array}{l}\mathrm{CDC} 1200 / \\
{[\mathrm{BMI}]\left[\mathrm{PF}_{6}\right]}\end{array}$} & $A$ & 156 & 89 & 40 & 93 \\
\hline & $C$ & 63 & 87 & 139 & 93 \\
\hline & $C-A$ & -93 & -2 & 99 & 0 \\
\hline & $C+A$ & 219 & 176 & 179 & 186 \\
\hline \multirow{4}{*}{$\begin{array}{c}\text { CDC 950 / } \\
{[\mathrm{BMI}]\left[\mathrm{PF}_{6}\right]}\end{array}$} & $A$ & 159 & 104 & 42 & 98 \\
\hline & $C$ & 67 & 107 & 124 & 99 \\
\hline & $C-A$ & -92 & 3 & 82 & 1 \\
\hline & $C+A$ & 226 & 211 & 166 & 197 \\
\hline \multirow{4}{*}{$\begin{array}{c}\text { CDC 800 / } \\
{\left[\mathrm{BMI}_{[}\left[\mathrm{PF}_{6}\right]\right.}\end{array}$} & $A$ & 152 & 88 & 29 & 70 \\
\hline & $C$ & 48 & 77 & 131 & 80 \\
\hline & $C-A$ & -104 & -11 & 102 & 10 \\
\hline & $C+A$ & 200 & 165 & 160 & 150 \\
\hline
\end{tabular}

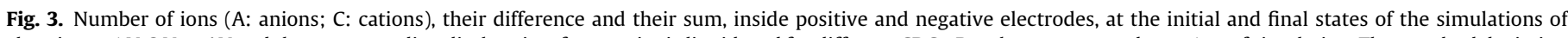

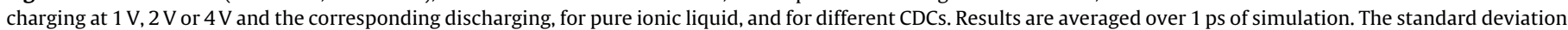
is around 5.

number of ions evolution) therefore happen with the same kinetics. This is not surprising since the total charge on one electrode directly compensates the charge of the difference $\boldsymbol{C}-\boldsymbol{A}$. If we now look accurately at the evolution of different characteristic times for the number of ions, we observe that the entrance of counter-ions occurs faster than the departure of co-ions.

The evolution of the number of ions as a function of time for charging simulations at a low potential difference $(1 \mathrm{~V})$ with and

\begin{tabular}{|c|c|c|c|c|c|}
\hline \multirow{2}{*}{\multicolumn{2}{|c|}{ Charging ( $0 \mathrm{~V}$ to $1 \mathrm{~V})$}} & \multicolumn{2}{|c|}{ Elec +} & \multicolumn{2}{|c|}{ Elec - } \\
\hline & & $t=0$ & $t=t_{f}$ & $t=0$ & $t=t_{f}$ \\
\hline \multirow{6}{*}{$\begin{array}{c}\mathrm{CDC} 1200 / \\
{[\mathrm{BMI}]\left[\mathrm{PF}_{6}\right]-} \\
\mathrm{ACN}\end{array}$} & $A$ & 32 & 50 & 34 & 22 \\
\hline & $C$ & 32 & 20 & 33 & 49 \\
\hline & $A C N$ & 338 & 351 & 340 & 322 \\
\hline & $C-A$ & 0 & -30 & -1 & 27 \\
\hline & $C+A$ & 64 & 70 & 67 & 71 \\
\hline & $C+A+A C N$ & 402 & 421 & 407 & 393 \\
\hline
\end{tabular}

\begin{tabular}{|c|c|c|c|c|c|}
\hline \multirow{2}{*}{\multicolumn{2}{|c|}{ Discharging ( $1 \mathrm{~V}$ to $0 \mathrm{~V})$}} & \multicolumn{2}{|c|}{ Elec +} & \multicolumn{2}{|c|}{ Elec - } \\
\hline & & $t=0$ & $t=t_{f}$ & $t=0$ & $t=t_{f}$ \\
\hline \multirow{6}{*}{$\begin{array}{c}\mathrm{CDC} 1200 / \\
{[\mathrm{BMI}]\left[\mathrm{PF}_{6}\right]-} \\
\mathrm{ACN}\end{array}$} & $A$ & 50 & 35 & 22 & 37 \\
\hline & $C$ & 20 & 3 & 49 & 38 \\
\hline & $A C N$ & 351 & 329 & 322 & 325 \\
\hline & $C-A$ & -30 & 0 & 27 & 1 \\
\hline & $C+A$ & 70 & 70 & 71 & 75 \\
\hline & $+A+A C N$ & 421 & 399 & 393 & 400 \\
\hline
\end{tabular}

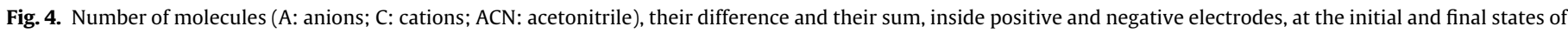

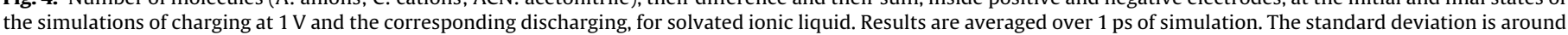
5. 


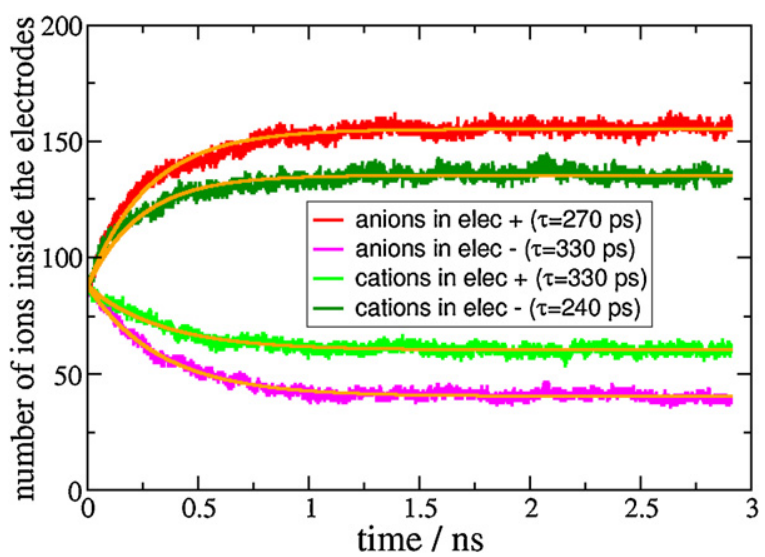

Fig. 5. Evolution of the number of ions inside the positive and negative electrodes during a charging process at $4 \mathrm{~V}$ for the pure ionic liquid. The plots are fitted by a monoexponential function (orange) and the characteristic times are given.

without solvent is presented in Fig. 6. When possible, the plots are fitted by a monoexponential exponential function and the associated characteristic times are given. In the case of pure ionic liquid, we find the same result as the one obtained at higher potential difference: the entrance of counter-ions occurs faster than the departure of co-ions. The exponential fit is of poorer quality with acetonitrile. It seems that the expulsion of co-ions is faster than counter-ions entrance in the presence of solvent ( $\tau \approx 1 \mathrm{~ns}$ vs $\approx$ $100 \mathrm{ps}$ ), whereas it is the contrary without solvent, whatever the
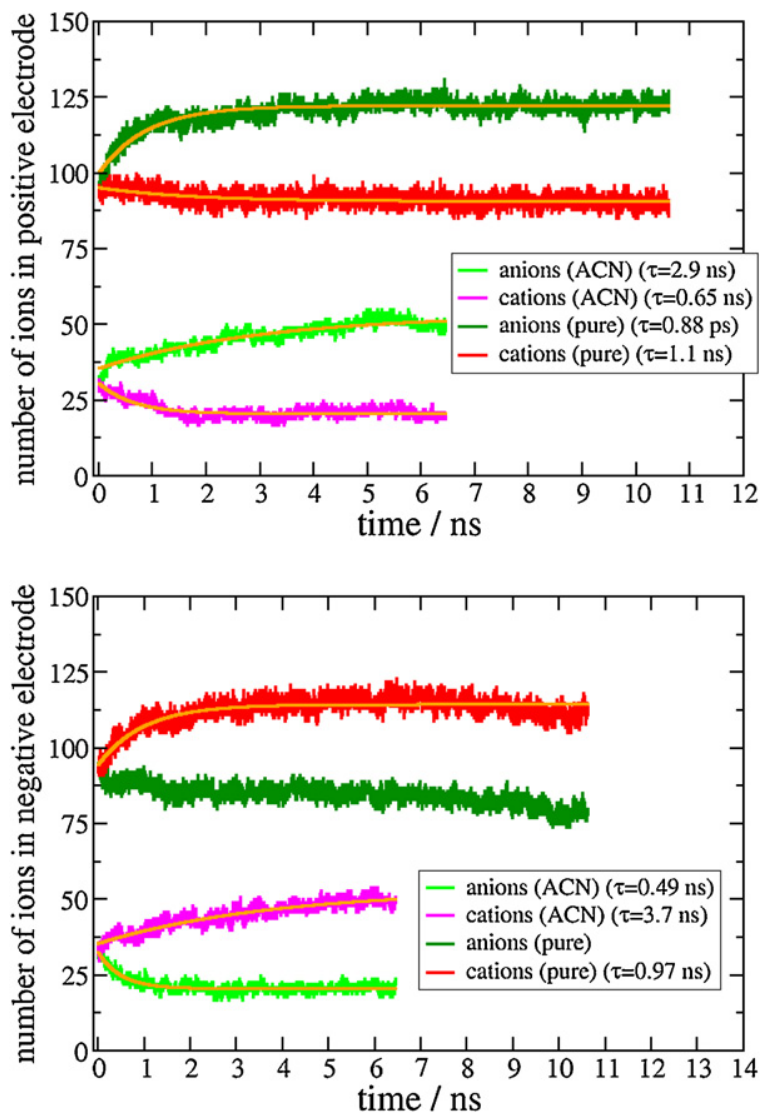

Fig. 6. Evolution of the number of ions inside the positive and negative electrodes during a charging process at $1 \mathrm{~V}$ in the cases with or without solvent. When possible, the plots are fitted by a monoexponential function (orange) and the characteristic times are given. The quality of the fit is poorer in the case of acetonitrile simulations, and also poorer than for simulations at high potential differences, as it was the case for the evolution of the total charges. voltage. Other simulations at various potential differences on solvated systems should be carried out to confirm this last result.

\subsection{Density profiles}

After analyzing the global quantities at the electrode scale, it is possible to perform more detailed analysis at the pore scale. It is easy to calculate ionic densities close from a planar surface [37]. In the case of the irregular surfaces of CDCs, this calculation becomes more delicate. A local accessible surface is defined by the center of a probe sphere of argon traveling on a grid along the electrode (experimentally, it is also argon that is commonly used to measure specific surface areas in the case of porous materials [38]). Locally, another planar surface, parallel to the previous one, can be defined by the contact between the radii of the carbon spheres and the probe sphere: it is the so called Connolly surface [39-41]. This methodology suffers from not distinguishing the surfaces that are actually accessible to the electrolyte (open pores) from the ones that are not (closed pores). Nevertheless, there are few closed pores in the investigated electrodes here, and not taking them into account just adds a small fixed shift on the distance of the ions to the surface. As we use data to make comparisons and not to conclude on absolute values, this does not influences our results.

In Fig. 7 we show the density profiles of anions and cations as a function of the distance to the carbon atoms surface, for different chosen times. Looking at the $y$-axis, we note that counter-ions are more numerous than co-ions, according to the polarization of the electrode. During the charging process, the counter-ions density increases keeping the same distance to the carbon. At 1 $\mathrm{V}$ potential differences (data not shown here), the co-ions density also decreases keeping the same distance to the carbon. The density maxima of counter-ions and co-ions are located at almost the same distance to the carbon (the cation seems in some cases to get closer from the surface than the anion, according to our previous results [16], but this could be an artefact caused by the coarse-grained model). Looking at the kinetics of evolution of the density peaks, we notice that most of the changes occurs during the first nanosecond, as it is the case with the number of ions evolution. After $\approx 6 \mathrm{~ns}$, the peaks do not evolve anymore. Again, we find the two regimes during the dynamical processes, one very fast, and the other slower. The same behaviour is obtained for the negative electrode. The analysis of the density profiles during the discharging processes gives the same results in line with the symmetric evolution of the total charges on electrodes.

For the charging at $1 \mathrm{~V}$, the density of ions evolves with the peak staying at the same distance to the carbon. We also observe that behaviour for the counter-ions density at $4 \mathrm{~V}$. However, at $4 \mathrm{~V}$, the co-ions density not only decreases (the integral of the plot at 2900 ps is inferior to the one at $100 \mathrm{ps}$ ) but also moves away from the carbon surface. A similar smaller shift is observed in simulations at $2 \mathrm{~V}$. At high potential differences, co-ions have the possibility to move away from the carbon surface, which facilitates the access of the counter-ions and thus their adsorption on the polarized electrode [42]. There is then a different organization of the ionic liquid at high potential differences. At $0 \mathrm{~V}$, the charge on the electrodes vanishes on average, counter-ions and co-ions can coexist close to the carbon without any preferential organization besides the one caused by steric effects between charged molecules. With a relatively high potential, co-ions move away from carbon to facilitate the approach of counter-ions and because the polarization of the electrode is unfavourable to them. Nevertheless, we do not observe two distinct layers of counter-ions and co-ions because their density peaks at $2900 \mathrm{ps}$ are located at $0.62 \mathrm{~nm}$ and $0.76 \mathrm{~nm}$ respectively, leading to a $0.14 \mathrm{~nm}$ difference, which is smaller than the sum of the radii of anions and cations (equal to $0.56 \mathrm{~nm}$ ). The same behaviour 

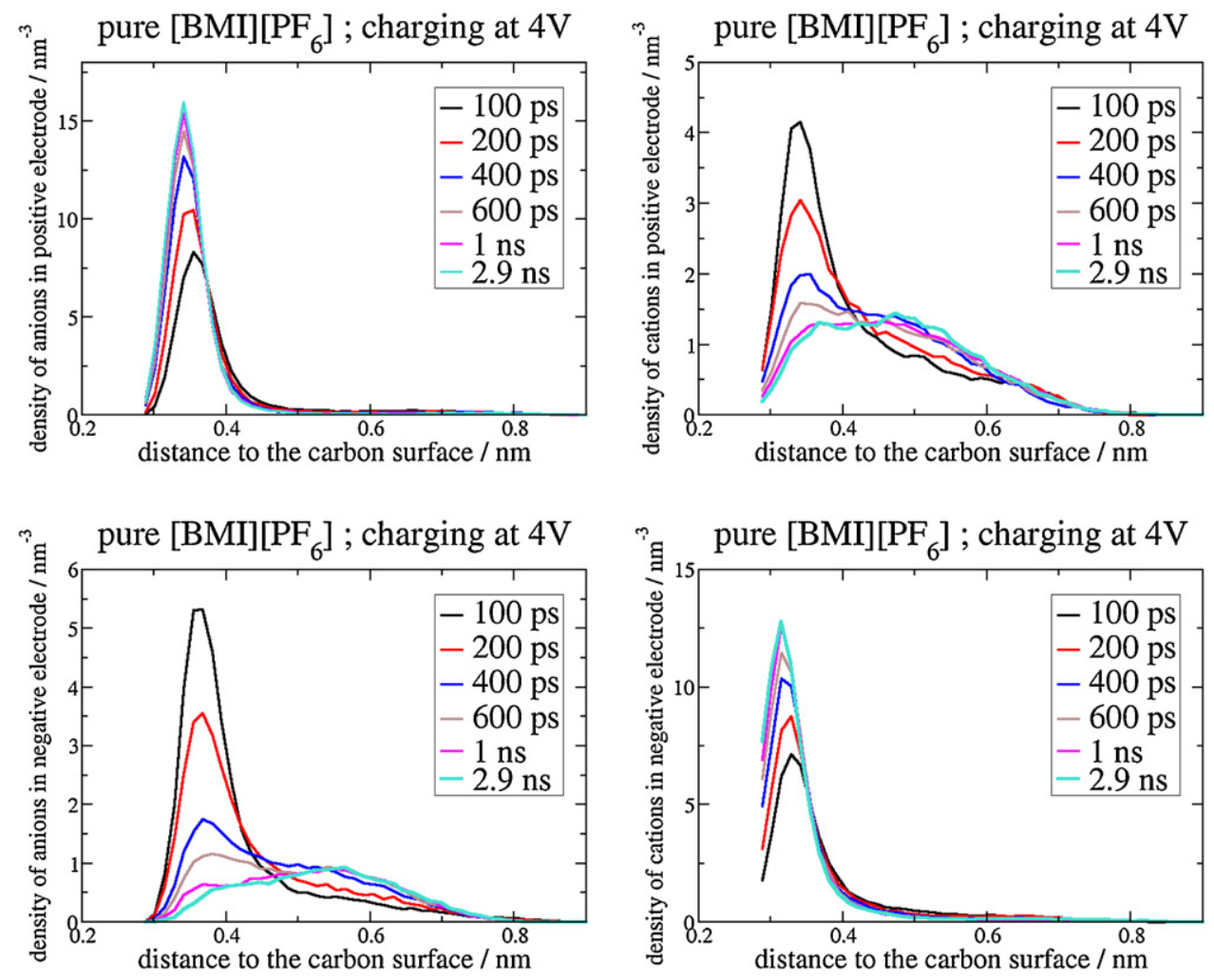

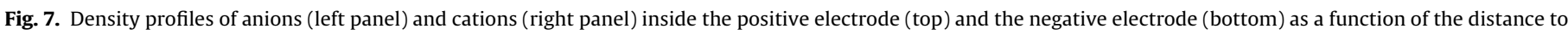

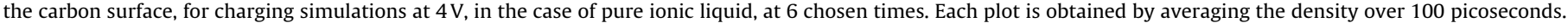
The black plot corresponds to the beginning of the simulation and that in light blue corresponds to the end of the simulation.
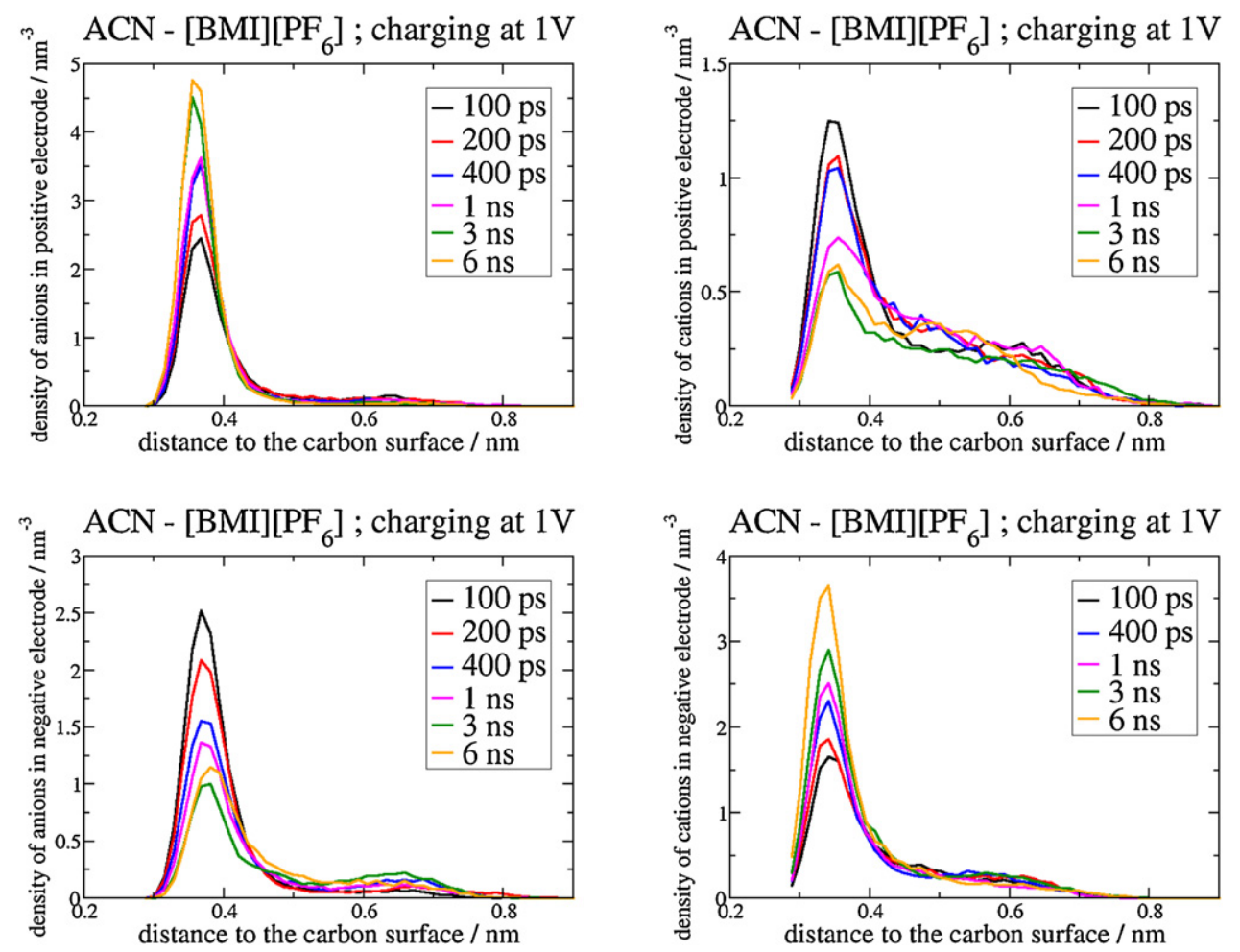

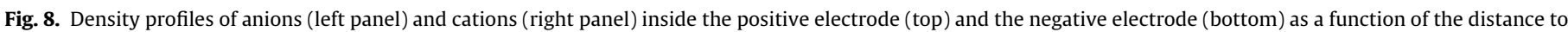

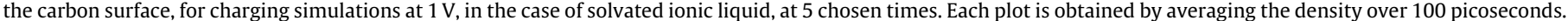
The black plot corresponds to the beginning of the simulation and that in orange corresponds to the end of the simulation. 
is obtained for the co-ions in the negative electrode. These conclusions on density profiles can also be found for CDC-950, which has the same average pore size of CDC-1200 (0.9 nm [29]), but a more irregular distribution of pore sizes (it presents a large pore in the middle of the electrode). This suggests that the average pore size is the structural parameter of main importance. In CDC-800, at $4 \mathrm{~V}$, we observe the removal of co-ions, but to a lesser extent than the other two electrode structures. Indeed, CDC-800 has a smaller average pore size $(0.75 \mathrm{~nm}$ [29]), thus preventing species to really move away or get closer to the carbon surfaces. Again, the analyses of the discharges give the same results, confirming the symmetric mechanism for the discharging process.

For the charging with solvent at $1 \mathrm{~V}$, we observe a slight shift of the density peak of co-ions (Fig. 8). This effect is more visible on the positive electrode, which mainly attracts anions, less voluminous and more mobile than cations. The density profiles for acetonitrile do not vary as a function of time, proving again that acetonitrile as a neutral molecule is not really affected by the polarization of the systems. Overall, adding solvent to pure electrolytes facilitates the charging, avoiding to apply a high voltage, because it allows the co-ions to move away from the surface.

\subsection{Looking at the pore scale}

In order to learn more about this removal of species from the carbon surfaces, we use our previous definition of the degree of confinement [28] distinguishing four different types of pores, from less confined to more confined: edges, planes, hollows, pockets. Fig. 9 presents the evolution of anions or cations in each type of pore during the charging of CDC- 1200 at $4 \mathrm{~V}$ with pure electrolyte. Counter-ions move towards high confinement sites, whilst co-ions move towards low confinement sites. The latter can never access pockets, for example. Furthermore, we can note the following result: co-ions go mostly from planes to edges, and counter-ions go mostly from edges to hollows and pockets. The fact that it is possible to identify distinct co-ion and a counter-ion behaviours suggests that these conclusions could be generalizable to other
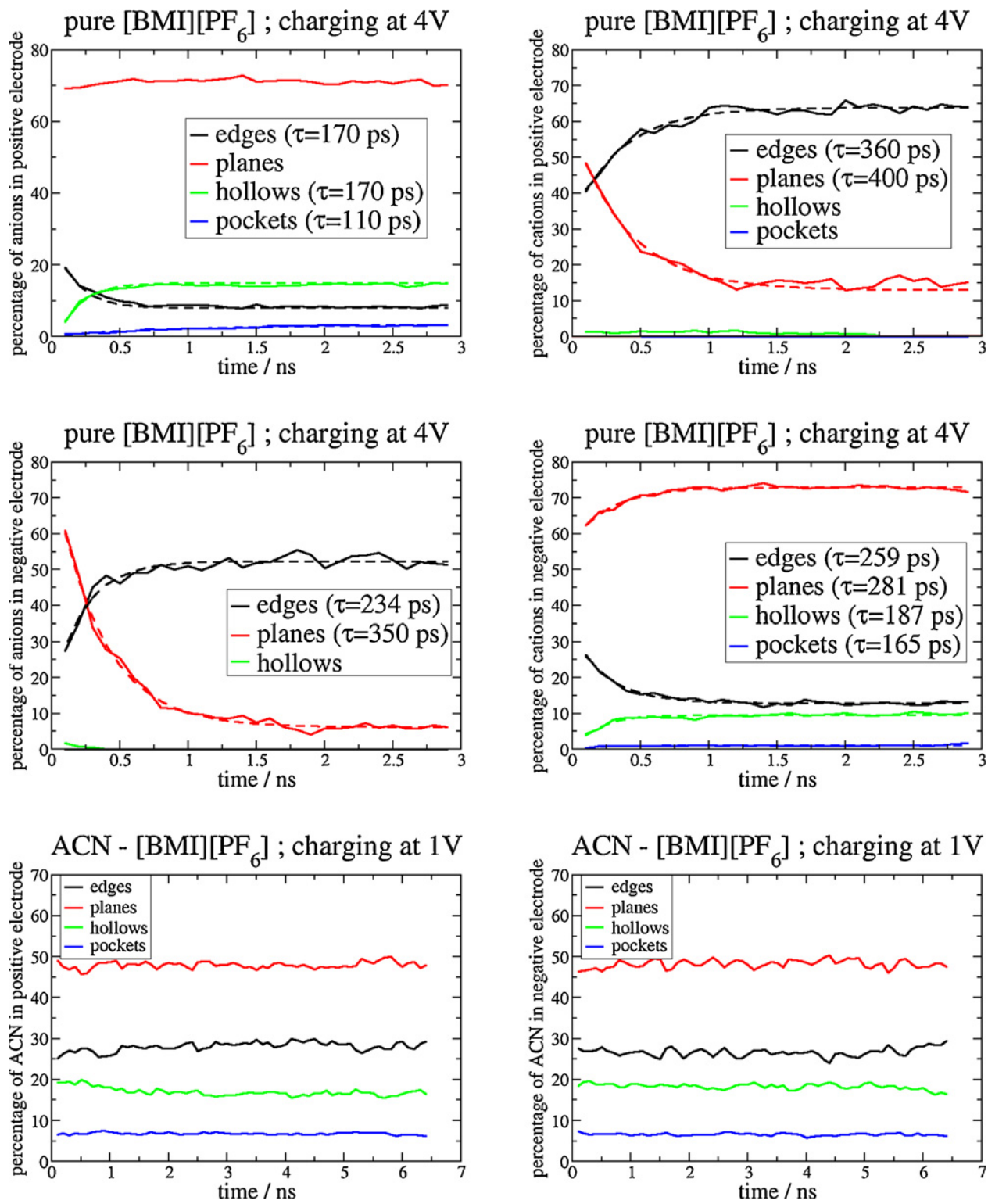

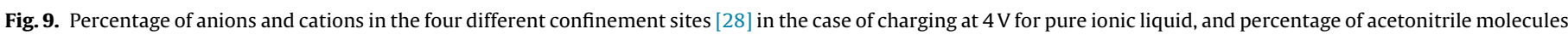
in the case of charging at $1 \mathrm{~V}$ for solvated electrolyte systems. When possible, the plots are fitted by a monoexponential function (dashed lines). 
ionic liquids, at least in the cases where there is a relative morphology difference between anions and cations.

When it is possible, the plots of Fig. 9 are fitted with a monoexponential function (indeed, not all observed quantities behave in a monoexponential way). From the corresponding characteristic times, we conclude that the reorganization of counter-ions is faster than that of the co-ions. Comparing these characteristic times to the ones already obtained in all this study, we can also conclude that the reorganization of counter-ions process is the fastest event. The analyses of the reorganization for the discharging processes leads to the same conclusions. For low potential differences, the same behaviours are observed, but the processes are slower, as for the charges or the number of ions inside the electrodes. Furthermore, the same behaviours are obtained for the three studied CDCs. For solvated systems, the plots are noisier, but we can also identify that the reorganization of co-ions occurs between edges and planes and that the one of counter-ions occurs mainly between planes and hollows. The pockets are almost never occupied by the ionic liquid because they contain the solvent, which is smaller $(r \approx 0.242 \mathrm{~nm}$ whereas for the cation, $r \approx 0.31 \mathrm{~nm}$, and for the anion, $r \approx 0.253 \mathrm{~nm}$ ). Finally, it is also interesting to note that for acetonitrile, there is no preference for a certain type of site. The proportion of acetonitrile molecules in each site is constant in time for either charging or discharging processes, according to what we already concluded for neutral molecules.

\section{Conclusions}

The results presented in this article allow us to conclude that charging and discharging are symmetrical processes that happen with the same kinetics. There are two regimes of response for the different quantities observed: first, a very fast regime and then, a slower second one. Furthermore, a high potential difference between electrodes accelerates the dynamical processes. The addition of solvent changes slightly the charging mechanism at the pore scale even if no major difference is seen at the electrode scale. A parallel can be drawn between the effects of increasing potential and adding solvent: the co-ions displacements is more evident and in particular their distance to the carbon electrodes can change more easily. In addition, we characterized the kinetics of the phenomena happening either at the pore scale or the electrode scale. Characteristic times have been identified, allowing to establish a classification for the charging mechanism, confirmed by the study of three different structures of carbon electrodes at various potentials:

- the inter-site reorganization of counter-ions is faster than that of co-ions

- the counter-ions entrance into the electrode is faster than the exit of co-ions, with pure ionic liquids. Other simulations with various solvent concentrations submitted to various potential differences would be necessary to confirm that the mechanism is opposite with solvent.

- the total charge on the electrode and the total number of ions inside the electrode evolves with the same characteristic time because the total charge on the electrode exactly compensates that of the ions inside the electrode, and reciprocally

This work provides knowledge on the behaviour of [BMI][PF 6$]$ ionic liquid based supercapacitors, and as emphasized in the article, some co-ions and counter-ions behaviours suggest that the results could be the extendable to other ionic liquids. Understanding precisely the functioning of supercapacitors is a major step for improving performances of these devices.

\section{Acknowledgments}

We acknowledge the support from the European Research Council under the European Union's Seventh Framework Programme (FP/2007-2013) / ERC grant Agreement n.102539 (Advanced grant, Ionaces project). We are grateful for the computing resources on OCCIGEN (CINES, French National HPC) and CURIE (TGCC, French National HPC) obtained through the project X2015096728.

\section{References}

[1] P. Simon, Y. Gogotsi, Capacitive Energy Storage in Nanostructured Carbon Electrolyte Systems, Accounts of Chemical Research 46 (2012) 1094-1103, http:// dx.doi.org/10.1021/ar200306b, URL http://dx.doi.org/10.1021/ar200306b.

[2] J. Chmiola, G. Yushin, Y. Gogotsi, C. Portet, P. Simon, P.-L. Taberna, Anomalous increase in carbon capacitance at pore sizes less than 1 nanometer, Science 313 (2006) 1760-1763, http://dx.doi.org/10.1126/science.1132195, URL http://www.sciencemag.org/content/313/5794/1760.

[3] M.D. Levi, N. Levy, S. Sigalov, G. Salitra, D. Aurbach, J. Maier, Electrochemical Quartz Crystal Microbalance (EQCM) Studies of Ions and Solvents Insertion into Highly Porous Activated Carbons, Journal of the American Chemical Society 132 (2010) 13220-13222, http://dx.doi.org/10.1021/ja104391g, URL http://dx.doi. org/10.1021/ja104391g.

[4] A.C. Forse, J.M. Griffin, H. Wang, N.M. Trease, V. Presser, Y. Gogotsi, P. Simon, C.P. Grey, Nuclear magnetic resonance study of ion adsorption on microporous carbide-derived carbon, Physical Chemistry Chemical Physics 15 (2013) 7722-7730, http://dx.doi.org/10.1039/C3CP51210J, URL http://pubs.rsc.org/ en/content/articlelanding/2013/cp/c3cp51210j.

[5] C. Merlet, A.C. Forse, J.M. Griffin, D. Frenkel, C.P. Grey, Lattice simulation method to model diffusion and NMR spectra in porous materials, The Journal of Chemical Physics 142 (2015) 094701, http://dx.doi.org/10.1063/1.4913368, URL http://scitation.aip.org/content/aip/journal/jcp/142/9/10.1063/1.4913368.

[6] M. Deschamps, E. Gilbert, P. Azais, E. Raymundo-Piñero, M.R. Ammar, P. Simon, D. Massiot, F. Beguin, Exploring electrolyte organization in supercapacitor electrodes with solid-state NMR, Nature Materials 12 (2013) 351-358, http://dx. doi.org/10.1038/nmat3567, URL http://www.nature.com/nmat/journal/v12/ n4/full/nmat3567.html.

[7] F.W. Richey, B. Dyatkin, Y. Gogotsi, Y.A. Elabd, Ion dynamics in porous carbon electrodes in supercapacitors using in situ infrared spectroelectrochemistry, Journal of the American Chemical Society 3 (2013) 12818-12826, http://dx.doi. org/10.1021/ja406120e, URL http://pubs.acs.org/doi/abs/10.1021/ja406120e.

[8] S. Boukhalfa, L. He, Y.B. Melnichenko, G. Yushin, Small-angle neutron scattering for in situ probing of ion adsorption inside micropores, Angewandte Chemie 52 (2013) 4618-4622, http://dx.doi.org/10.1002/anie.201209141, URL http:// onlinelibrary.wiley.com/doi/10.1002/anie.201209141/abstract.

[9] I. Humer, O. Bethge, M. Bodnarchuk, M. Kovalenko, M. Yarema, W. Heiss, H.P. Huber, M. Hochleitner, P. Hinterdorfer, F. Kienberger, J. Smoliner, Scanning microwave microscopy and scanning capacitance microscopy on colloidal nanocrystals, Journal of Applied Physics 109 (2011) 064313, http://dx.doi.org/ 10.1063/1.3553867, URL http://scitation.aip.org/content/aip/journal/jap/109/ 6/10.1063/1.3553867.

[10] J. Vatamanu, O. Borodin, G.D. Smith, Molecular Simulations of the Electric Double Layer Structure, Differential Capacitance, and Charging Kinetics for N-Methyl-N-propylpyrrolidinium Bis(fluorosulfonyl)imide at Graphite Electrodes, The Journal of Physical Chemistry B 115 (2011) 3073-3084, http://dx. doi.org/10.1021/jp2001207, URL http://dx.doi.org/10.1021/jp2001207.

[11] J. Vatamanu, O. Borodin, G.D. Smith, Molecular Insights into the Potential and Temperature Dependences of the Differential Capacitance of a Room-Temperature Ionic Liquid at Graphite Electrodes, Journal of the American Chemical Society 132 (2010) 14825-14833, http://dx.doi.org/10.1021/ ja104273r, URL http://dx.doi.org/10.1021/ja104273r.

[12] L. Xing, J. Vatamanu, O. Borodin, D. Bedrov, On the Atomistic Nature of Capacitance Enhancement Generated by Ionic Liquid Electrolyte Confined in Subnanometer Pores, The Journal of Physical Chemistry Letters 4 (2013) 132-140, http://dx.doi.org/10.1021/jz301782f, URL http://pubs.acs.org/doi/ abs/10.1021/jz301782f.

[13] A.A. Lee, S. Kondrat, Charging dynamics of supercapacitors with narrow cylindrical nanopores, Nanotechnology 25 (2014) 315401, http://dx.doi.org/ 10.1088/0957-4484/25/31/315401, URL http://iopscience.iop.org/article/10. 1088/0957-4484/25/31/315401/meta.

[14] S. Kondrat, A. Kornyshev, Superionic state in double-layer capacitors with nanoporous electrodes, Journal of Physics: Condensed Matter 23 (2011) 022201, http://dx.doi.org/10.1088/0953-8984/23/2/022201, URL http:// stacks.iop.org/0953-8984/23/i=2/a=022201? key=crossref.96dc46f1 f885 affabbc854cc76000fof.

[15] J. Vatamanu, Z. Hu, D. Bedrov, C. Perez, Y. Gogotsi, Increasing Energy Storage in Electrochemical Capacitors with Ionic Liquid Electrolytes and Nanostructured Carbon Electrodes, The Journal of Physical Chemistry Letters 4 (2013) 2829-2837, http://dx.doi.org/10.1021/jz401472c, URL http://dx.doi. org/10.1021/jz401472c. 
[16] C. Merlet, B. Rotenberg, P.A. Madden, P.-L. Taberna, P. Simon, Y. Gogotsi, M. Salanne, On the molecular origin of supercapacitance in nanoporous carbon electrodes, Nature Materials 11 (2012) 306-310, http://dx.doi.org/10.1038/ nmat3260, URL http://www.nature.com/nmat/journal/v11/n4/full/nmat3260. html.

[17] C. Pean, B. Daffos, C. Merlet, B. Rotenberg, P.-L. Taberna, P. Simon, M. Salanne, Single electrode capacitances of porous carbons in neat ionic liquid electrolyte at $100^{\circ} \mathrm{C}$ : a combined experimental and modeling approach, Journal of the Electrochemical Society 162 (2015) A5091-A5095, http://dx.doi.org/10.1149/ 2.0151505jes, URL http://jes.ecsdl.org/content/162/5/A5091.abstract.

[18] C. Merlet, M. Salanne, B. Rotenberg, P.A. Madden, Imidazolium Ionic Liquid Interfaces with Vapor and Graphite: Interfacial Tension and Capacitance from Coarse-Grained Molecular Simulations, The Journal of Physical Chemistry C 115 (2011) 16613-16618, http://dx.doi.org/10.1021/jp205461g, URL http://pubs. acs.org/doi/abs/10.1021/jp205461g.

[19] C. Merlet, M. Salanne, B. Rotenberg, New Coarse-Grained Models of Imidazolium Ionic Liquids for Bulk and Interfacial Molecular Simulations, The Journal of Physical Chemistry C 116 (2012) 7687-7693, http://dx.doi.org/10.1021/ jp3008877, URL http://pubs.acs.org/doi/abs/10.1021/jp3008877.

[20] C. Merlet, M. Salanne, B. Rotenberg, P.A. Madden, Influence of solvation on the structural and capacitive properties of electrical double layer capacitors, Electrochimica Acta 101 (2012) 262-271, http://dx.doi.org/10.1016/j. electacta.2012.12.107, URL http://www.sciencedirect.com/science/article/pii/ S0013468612020816.

[21] S. Kondrat, P. Wu, R.A. Qiao, A.A. Kornyshev, Accelerating charging dynamics in subnanometre pores, Nature Materials 13 (2014) 387-393, http://dx. doi.org/10.1038/nmat3916, URL http://www.nature.com/nmat/journal/v13/ n4/full/nmat3916.html.

[22] Y. He, J. Huang, B.G. Sumpter, A.A. Kornyshev, R. Qiao, Dynamic Charge Storage in Ionic Liquids-Filled Nanopores: Insight from a Computational Cyclic Voltammetry Study, The Journal of Physical Chemistry Letters 6 (2014) 22-30, http:// dx.doi.org/10.1021/jz5024306, URL http://dx.doi.org/10.1021/jz5024306.

[23] W.-Y. Tsai, P.-L. Taberna, P. Simon, Electrochemical Quartz Crystal Microbalance (EQCM) Study of Ion Dynamics in Nanoporous Carbons, Journal of the American Chemical Society 136 (2014) 8722-8728, http://dx.doi.org/10.1021/ ja503449w, URL http://dx.doi.org/10.1021/ja503449w.

[24] F.W. Richey, C. Tran, V. Kalra, Y.A. Elabd, Ionic liquid dynamics in nanoporous carbon nanofibers in supercapacitors measured with in operando infrared spectroelectrochemistry, Journal of Physical Chemistry C 118 (2014) 21846-21855, http://dx.doi.org/10.1021/jp506903m, URL http://pubs.acs.org/ doi/abs/10.1021/jp506903m.

[25] J. Griffin, A. Forse, W.-Y. Tsai, P.-L. Taberna, P. Simon, C.P. Grey, In situ nmr and quartz crystal microbalance techniques reveal the electric doublelayer structure of supercapacitor electrodes, Nature Materials 14 (2015) 812, http://dx.doi.org/10.1038/nmat4318, URL http://www.nature.com/nmat/ journal/v14/n8/abs/nmat4318.html.

[26] C. Merlet, C. Pean, B. Rotenberg, P.A. Madden, P. Simon, M. Salanne, Simulating Supercapacitors: Can We Model Electrodes As Constant Charge Surfaces? The Journal of Physical Chemistry Letters 4 (2013) 264-268, http://dx.doi.org/10. 1021/jz3019226, URL http://dx.doi.org/10.1021/jz3019226.

[27] C. Pean, C. Merlet, B. Rotenberg, P.A. Madden, P.-L. Taberna, B. Daffos, M. Salanne, P. Simon, On the Dynamics of Charging in Nanoporous Carbon-Based Supercapacitors, ACS Nano 8 (2014) 1576-1583, http://dx.doi.org/10.1021/ nn4058243, URL http://dx.doi.org/10.1021/nn4058243.

[28] C. Merlet, C. Pean, B. Rotenberg, P.A. Madden, B. Daffos, P.-L. Taberna, P. Simon, M. Salanne, Highly confined ions store charge more efficiently in supercapacitors, Nature Communications 4 (2013) 2701, http://dx.doi.org/ 10.1038/ncomms3701, URL http://www.nature.com/ncomms/2013/131029/ ncomms3701/full/ncomms3701.html.
[29] J. Palmer, A. Llobet, S.-H. Yeon, J. Fischer, Y. Shi, Y, Gogotsi, K. Gubbins, Mod eling the structural evolution of carbide-derived carbons using quenched molecular dynamics, Carbon 48 (2010) 1116-1123, http://dx.doi.org/10.1016 j.carbon.2009.11.033, URL http://www.sciencedirect.com/science/article/pii/ S0008622309007684.

[30] D. Roy, N. Patel, S. Conte, M. Maroncelli, Dynamics in an idealized ionic liquid model, Journal of Physical Chemistry B 114 (2010) 8410-8424, http:// dx.doi.org/10.1021/jp1004709, URL http://pubs.acs.org/doi/abs/10.1021/ jp1004709.

[31] D. Roy, M. Maroncelli, An Improved Four-Site Ionic Liquid Model, The Journal of Physical Chemistry B 114 (2010) 12629-12631, http://dx.doi.org/10.1021/ jp108179n, URL http://dx.doi.org/10.1021/jp108179n.

[32] D.M. Edwards, P. Madden, I. McDonald, A computer simulation study of the dielectric properties of a model of methyl cyanide, Molecular Physics 51 (1984) 1141-1161, http://dx.doi.org/10.1080/00268978400100731, URL http://www.ingentaconnect.com/content/tandf/tmph/1984/00000051/ $00000005 /$ art00005.

[33] S.K. Reed, O.J. Lanning, P.A. Madden, Electrochemical interface between an ionic liquid and a model metallic electrode, The Journal of Chemical Physics 126 (2007) 084704, http://dx.doi.org/10.1063/1.2464084, URL http://jcp.aip. org/resource/1/jcpsa6/v126/i8/p084704_s1.

[34] T.R. Gingrich, M. Wilson, On the Ewald summation of Gaussian charges for the simulation of metallic surfaces, Chemical Physics Letter 500 (2010) 178-183, http://dx.doi.org/10.1016/j.cplett.2010.10.010, URL http://www. sciencedirect.com/science/article/B6TFN-51696XX-2/2/071a9d8af52b303 caffcb3ff8b637fdc.

[35] J.I. Siepmann, M. Sprik, Influence of surface topology and electrostatic potential on water/electrode systems, The Journal of Chemical Physics 102 (1995) 511-524, http://dx.doi.org/10.1063/1.469429, URL http://scitation.aip. org/content/aip/journal/jcp/102/1/10.1063/1.469429.

[36] H. Tokuda, K. Hayamizu, K. Ishii, M.A.B.H. Susan, M. Watanabe, Physicochemical Properties and Structures of Room Temperature Ionic Liquids. 1. Variation of Anionic Species, The Journal of Physical Chemistry B 108 (2004) 16593-16600, http://dx.doi.org/10.1021/jp047480r, URL http://pubs.acs.org/ doi/abs/10.1021/jp047480r.

[37] K. Kirchner, T. Kirchner, V. Ivanistsev, M.V. Fedorov, Electrical double layer in ionic liquids: Structural transitions from multilayer to monolayer structure at the interface, Electrochimica Acta 110 (2013) 762-771, http://dx.doi.org 10.1016/j.electacta.2013.05.049, URL http://www.sciencedirect.com/science/ article/pii/S0013468613009547.

[38] S. Brunauer, P.H. Emmett, E. Teller, Adsorption of gases in multimolecular layers, Journal of American Chemical Society 60 (1938) 309-319, http:/ dx.doi.org/10.1021/ja01269a023, URL http://dx.doi.org/10.1021/ja01269a023.

[39] M.L. Connoly, Analaytical molecular-surface calculation, Journal of Applied Crystallography 16 (1983) 548-558, http://dx.doi.org/ 10.1107/S0021889883010985, URL http://scripts.iucr.org/cgi-bin/paper? S0021889883010985.

[40] M.L. Connolly, Computation of molecular volume, Journal of the American Chemical Society 107 (1985) 1118-1124, http://dx.doi.org/10.1021/ ja00291a006, URL http://dx.doi.org/10.1021/ja00291a006.

[41] L. Gelb, K.E. Gubbins, Pore size distributions in porous glasses: a computer simulation study, Langmuir 15 (1999) 305, http://dx.doi.org/10.1021/la9808418, URL http://pubs.acs.org/doi/abs/10.1021/la9808418.

[42] C. Pean, B. Daffos, B. Rotenberg, P. Levitz, M. Haefele, P.-L. Taberna, P. Simon, M. Salanne, Confinement, desolvation, and electrosorption effects on the diffusion of ions in nanoporous carbon electrodes, Journal of American Chemical Society doi:10.1021/jacs.5b07416. URL http://pubs.acs.org/doi/pdf/10.1021/jacs. $5 \mathrm{~b} 07416$. 